\begin{tabular}{|c|c|}
\hline 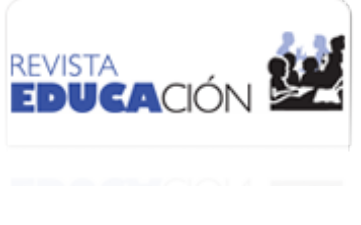 & $\begin{array}{l}\text { Revista Educación } \\
\text { ISSN: 0379-7082 } \\
\text { ISSN: } 2215-2644 \\
\text { revedu@gmail.com } \\
\text { Universidad de Costa Rica } \\
\text { Costa Rica }\end{array}$ \\
\hline
\end{tabular}

\title{
Profesorado universitario: Emisor de valores éticos y morales en México
}

\author{
Cantú-Martínez, Pedro César \\ Profesorado universitario: Emisor de valores éticos y morales en México \\ Revista Educación, vol. 42, núm. 1, 2018 \\ Universidad de Costa Rica, Costa Rica \\ Disponible en: http://www.redalyc.org/articulo.oa?id=44051918009 \\ DOI: https://dx.doi.org/10.15517/revedu.v42i1.23479
}

Esta obra está bajo una Licencia Creative Commons Atribución-NoComercial-SinDerivar 3.0 Internacional. 


\section{Profesorado universitario: Emisor de valores éticos y morales en México}

\section{University Faculty: Issuer of Ethical and Moral Values in Mexico}

Pedro César Cantú-Martínez [1]

Universidad Autónoma de Nuevo León, México

DOI: https://dx.doi.org/10.15517/revedu.v42i1.23479

pedro.cantum@uanl.mx

Redalyc: http://www.redalyc.org/articulo.oa?id=44051918009

Recepción: 07 Marzo 2016

Aprobación: 13 Julio 2017

\section{RESUMEN:}

El presente artículo de revisión aborda la labor del profesorado universitario en México, que es de suma importancia para la sociedad, para dar respuesta a las problemáticas y a los nuevos desafíos sociales. Su quehacer y pensar incide además en la formación de sus estudiantes, haciendo de la enseñanza superior una dinámica participativa, que le permite erigirse en guía, al proporcionar elementos técnicos suficientes y proveerles de habilidades personales que se manifiesten en valores éticos y morales, lo cual sucede mediante su interacción y la mediación del conocimiento que imparte. Otorgando a sus estudiantes, así, el fervor por lo humano, el conocimiento y los valores compartidos, mediante la relación natural que supera las aulas y la misma profesión que logra edificarlos moralmente.

Palabras Clave: ética, moral, valores, profesorado, universidad.

\section{Abstract:}

This article discusses the daily work of a university professor in Mexico, which is very important for society to respond to the problems and to new social challenges. Professors work and thinking also affects the development of their students, doing of higher education a participatory dynamic that allows students to establish itself as a guide, to provide sufficient technical elements, and provide them with personal skills that are manifested in ethical and moral values, that happens through interaction and mediation of knowledge it imparts. Thus, giving the fervor for humanity, knowledge and shared values, using the natural relation that exceeds the classrooms and the same profession that manages to build them morally.

KEYWORDS: ethics, moral, values, teacher, university.

\section{INTRODUCCIÓN}

Hoy la educación superior ha adquirido mayor relevancia, debido a las profundas transformaciones que se suscitan en el mundo, motivadas, en parte, por el presuroso progreso de la ciencia y sus aplicaciones, como también se encuentra fuertemente ligada a la construcción de un ser humano que pueda insertarse en la sociedad productivamente y llevar una mejor calidad de vida, esto es, de una manera más sustentable, para que pueda ser un actor social y contribuir a la resolución de las amplias brechas y asimetrías sociales existentes que afrontará, aplicando el conocimiento que le fue impartido de una forma escolarizada como aquel otro, que se generó a través de la investigación.

En este sentido, en México, el papel de las instituciones de educación superior (IES) en los procesos de trasformación es bastante relevante, porque en estos espacios se modelan los recursos humanos de más alto nivel, que las nuevas circunstancias sociales demandan; pero, además, es donde se forman seres humanos,

\section{NotAS DE AUTOR}

[1] Doctorado en Ciencias Biológicas por la Universidad Autónoma de Nuevo León (UANL). Profesor de la UANL, adscrito a la Facultad de Ciencias Biológicas. Participa en el Instituto de Investigaciones Sociales. Ha sido colaborador con en la Organización Panamericana de la Salud y Comisión de Salud Fronteriza México-Estados Unidos. Miembro del Sistema Nacional de Investigadores - CONACYT: Nivel 1. Miembro del Cuerpo Académico Ciencias Exactas y Desarrollo Humano UANL-CA-181 con nivel consolidado. Su línea de investigación es calidad de vida e indicadores de sustentabilidad ambiental. 
comprometidos con el desarrollo y la humanidad (Knight, 2006). Es así que en este contexto, el papel de la labor del profesorado universitario es de suma trascendencia, ya que se ha constituido en un ente formador de opinión y en una veta inspiradora para sus estudiantes. El profesorado universitario también se constituye en el motor dinamizador de la IES, para que estas incidan en la ambiciosa tarea de ascender a la sociedad a una mejor calidad de vida, que se refleje en los distintos colectivos sociales que la integran.

Partiendo de lo anterior, cito a Masiá (1995, p. 12): "hay tres clases de médicos. Los regulares, los buenos y los buenísimos. Los regulares sólo curan enfermedades. Los buenos además de enfermedades, curan enfermos. Los buenísimos, además de curar enfermedades y enfermos, curan al país”. Por lo tanto, haciendo una analogía de la cita anterior con el quehacer del profesorado universitario, nos hacemos la siguiente pregunta ¿cuál es la labor del profesorado universitario en México, para dejar un legado de valores éticos y morales en sus estudiantes, que sea útil para erigir a ese ser dúctil, vulnerable, pleno de tantas ilusiones como temores, que somos los seres humanos? Para responder a este cuestionamiento será necesario transitar por el papel de la educación superior, para posteriormente describir la figura de la profesora y profesor universitario en la actualidad en nuestro país y finalmente abordar su representación como un agente ético, moral y de integridad académica.

\section{PAPEL De la educación SUPerior}

Laudadío (2015, p. 165) menciona que las "políticas educativas dependen de realidades muy diferentes en función de su historia previa, tradiciones, posibilidades económicas y prioridades en educación. Cada país debe encontrar las políticas adecuadas según sus propias circunstancias”. Es así como, en la actualidad, se ha podido ser testigo de los múltiples cambios que han ocurrido en la educación superior en el mundo. Particularmente, durante las últimas décadas, donde se han observado, en el plano internacional, hechos como la masificación y la gradual pluralidad de estudiantes, hasta las evidentes crisis provocadas por la disminución de fondos económicos para sustentar estas (Del Mastro y Monereo, 2014); como también, la inserción en sus operaciones de una cultura de calidad y de responsabilidad social (Cantú-Martínez, 2013; Ross, 2010).

De manera particular, la orientación en la formación de estudiantes ha cambiado también, en México; de una centrada inicialmente en la enseñanza, ha transitado hacia el aprendizaje, y ahora ha conmutado hacia competencias, donde la incorporación de las nuevas tecnologías forma una parte sustantiva de la instrucción. Igualmente, también se reconoce que la globalización actualmente existente en el plano de la educación superior ha orillado a las instituciones educativas en nuestro país a involucrarse, cada vez más, en actividades relacionadas con la ciencia y tecnología (Delgado, 2007; Zabalza, 2004).

Por lo tanto, indiscutiblemente, el escenario universitario es el lugar, por excelencia, donde se crean los espacios para dar respuesta a las problemáticas actuales y a los nuevos retos sociales en la nación. De tal manera, en este contexto se yergue un clamor con grado de exigencia social para las IES en el país, el cual consiste en no sentirse satisfechas únicamente, al trasmitir conocimiento y dar resolución científica a las eventualidades y desafíos, sino además les corresponde construir la humanización de la vida política y social de México, con el poder que le es conferido por la sociedad (Cantú-Martínez, 2015a; Chapela y Cerda, 2010; Gorrochotegui, 2005). Consecuentemente, además, les incumbe formar, como señala Zabalza (2004, p. 22), "líderes tanto del mundo social como del científico y artístico", que estén en contacto y sean sensibles al contexto social, económico y ambiental que subsiste en el país, con el fin de encontrar los cauces para una convivencia más pacífica, equitativa y justa.

Sin embargo, es palpable la influencia que ejerce la globalización, mediante el posicionamiento de distintos marcos de referencia social, que se contraponen con el contexto de lo que sucede en el aquí y ahora donde se encuentra asentada la IES (Cantú-Martínez, 2014). Esto influye en la formación del alumnado universitario, 
por lo cual Linares y Fraile (2012, p. 121) afirman que "la educación superior no escapa al impacto de los cambios sociales, económicos y políticos que acontecen en el panorama global”.

En este contexto, el precepto ético es fundamental, como señala categóricamente Cantú-Martínez (2015b):

Es necesario que el sistema educativo superior [en México] responda a los problemas reales de la sociedad actual y posibilite la participación activa de los estudiantes y docentes, para convertirse en parte de la solución, donde los actores universitarios trabajen en una cultura de colaboración que haga posible este proyecto de ética educativa. (p. 93)

Lo anterior toma sentido debido a que las experiencias implementadas en el orbe, en distintos segmentos sociales, han demostrado que la creación de bienestar social está vinculada a la utilización de conocimientos emanados de la actividad tecnocientífica y de una proporción elevada de personas involucradas con estudios profesionales (Mungaray, Ocegueda y Sánchez, 2002). Para acceder a este proyecto de ética educativa en el contexto de la educación superior en México, es pertinente considerar una formación académica integral del estudiantado, la cual se encuentre demarcada por las peculiaridades disciplinares de la formación universitaria, que permitan:

A los egresados examinar y considerar, en su justo valor, las disimiles demostraciones socioambientales que le circundan, las cuales son evidenciadas por los movimientos sociales y civiles, las nuevas relaciones de la sociedad civil con el Estado y la ciencia, y las preocupaciones que emergen en la colectividad social por la paz, el ambiente y el desarrollo humano. (CantúMartínez, 2014, p. 28)

Por lo tanto, la educación superior en nuestro país, según señala Camarillo Hinojosa (2002, p. 29), debe evolucionar "por ser un hecho social que implica la correlación de los procesos históricos". Es así que la educación superior se yergue como proceso de formación permanente, de orden personal, sociocultural, el cual se cimienta en la búsqueda de construcción integral del ser humano. Particularmente, porque desde la perspectiva de la situación socioeconómica y política que permanece en el concierto internacional y planos nacionales en muchos lugares, como es el caso de nuestra nación, aún persisten con mucha indignación las injusticias, la carencia de solidaridad y cooperación entre los seres humanos para cambiar y transformar la sociedad, donde el individualismo exacerbado ha empobrecido la conciencia y el tejido social en que subsistimos. En este sentido, Sánchez Puente (2004), lo advierte al indicar terminantemente:

Las universidades tienen que aportar su cuota. Ésta, para el caso del doctorado, consiste en capacitar cuadros competentes que se integren consistentemente al sector productivo de bienes y servicios, así como en formar investigadores entrenados en la generación de conocimientos científicos, sociales, humanísticos y en los estudios de innovación y desarrollo tecnológicos en determinadas áreas prioritarias, de acuerdo con las necesidades y aspiraciones de desarrollo de la sociedad civil en su conjunto. (p. 69-70)

Por último, como menciona Cullen (2004), la educación superior toma trascendencia, ya que el carecer de ella es encontrarnos en un plano de desinformación y aislamiento, situación que nos paraliza, tanto individualmente como colectivamente. Por lo que acceder a ella y aspirar a una mejor calidad de vida, equidad y justicia social nos lleva a comprender que estos preceptos son valores de cambio necesarios, para alcanzar una vida buena y una libertad digna; todo esto, otorgado a través de las actividades que realizan las profesoras y los profesores universitarios en el seno de las IES.

\section{El Profesorado uniVersitario en la ACTUALIDAd en MÉXico}

¿Qué se entiende por profesora o profesor universitario? Aunque su expresión es singular, en contenido el concepto refiere a pluralidad, a un grupo de personas que comparten sentimientos de identidad como pertenencia, y representan un segmento de la sociedad, que trasciende porque se ocupan de enseñar a otras personas, que pretenden instruirse sobre el arte o ciencia que este grupo docente domina profesionalmente. El 
término de grupo una forma correcta de nominarlos, ya que de acuerdo con Arévalo (2007, p. 20), "el termino grupo proviene del italiano gruppo, palabra que se usaba en las bellas artes para designar a un conjunto de personas que perseguían un fin común”. Estos grupos se particularizan por ser copartícipes de actividades e interacciones regulares que, además, se inclinan a actuar de forma unitaria, que muestran necesidades y pretenden fines y objetivos determinados. Es así que al hablar del profesorado universitario nos referiremos a la condición de grupo, en cuyas personas, como advierte Lolas (2002, p. 15), reside la "posesión de un saber formal, cultivado en universidades y permanentemente renovado por la investigación, [que] lo aplican a problemas y demandas de la vida cotidiana".

En este sentido, en México hasta el año 2013 operó el Programa de Mejoramiento del Profesorado (PROMEP), instaurado desde 1996 para dar contestación a las recomendaciones realizadas por la UNESCO al país de establecer un sistema para fortalecer las capacidades en materia de investigación-docencia de las profesoras y los profesores universitarios. Recientemente, en el 2014, este programa ha sido relevado y enriquecido en sus propuestas por el Programa para el Desarrollo Profesional Docente (PRODEP) para la Educación Superior (Secretaria de Educación Pública, 2014). Este nuevo programa de gobierno tiene como propósito vigorizar los proyectos de formación educativa, como también de actualización en materia de carácter académico, capacitación e investigación, que fortalezcan las capacidades de investigación-docencia del profesorado universitario; con la finalidad de asegurar la continuidad de la calidad en la educación superior, como también el recambio generacional de la planta docente. Hoy en día, este programa tiene una cobertura en 714 IES en el territorio nacional, que incluye universidades públicas estatales (UPE), UPE de apoyo solidario, IES federales, universidades politécnicas, universidades tecnológicas, institutos tecnológicos federales, escuelas normales, institutos tecnológicos descentralizados y universidades interculturales.

Por otra parte, en 2015, como cita la Asociación Nacional de Universidades e Instituciones de Educación Superior (ANUIES, 2015) durante el ciclo escolar 2012-2013 en México, se contó con una planta de 352,007 docentes de universidades con distintos niveles de estudio que involucraban personal con un tiempo de dedicación muy variado como tiempo completo, medio tiempo y por horas, como también con un diferencial de grados académicos como doctorado, maestría, especialidad, licenciatura y técnico superior (ver Tabla 1).

Dicho lo anterior, es relevante mencionar que las IES en México, como quizás en muchos otros países, en gran medida son el resultado del quehacer y pensar de su personal docente, cuya tarea hoy involucra un aprendizaje y actualización permanente (Chávez y Benavides, 2011). Esencialmente cuando la realidad social y científica, en México como en el concierto internacional cambia vertiginosamente, influyendo así constantemente en los contenidos de los programas analíticos de las materias que imparten, como también del avance tecnocientífico que va enriqueciendo las formas prácticas de plasmar el conocimiento (Cerrillo y Izuzquiza, 2005). Por esta razón, en la medida que las IES puedan asegurar este buen desempeño de sus profesores y profesoras, tienen garantizado, en un gran porcentaje, la excelencia como instancia de educación superior, la cual es legitimada por alguna autoridad, a través de las acreditaciones que posee institucionalmente y de la certificación de su profesorado, tanto de forma individual como grupalmente (Lolas, 2002). 
TABLA 1

Personal docente que atendió los diferentes niveles de educación superior en México durante el período 2012-2015

\begin{tabular}{|c|c|c|c|c|c|c|}
\hline \multicolumn{7}{|c|}{ Grado del personal docente } \\
\hline $\begin{array}{l}\text { Niveles de } \\
\text { educación } \\
\text { superior }\end{array}$ & $\begin{array}{l}\text { Técnico } \\
\text { Superior }\end{array}$ & Licenciatura & Especialidad & Maestría & Doctorado & Total \\
\hline $\begin{array}{l}\text { Técnico } \\
\text { Superior } \\
\text { Universitario }\end{array}$ & $\begin{array}{c}802 \\
(0.22 \%)\end{array}$ & $\begin{array}{c}7600 \\
(2.15 \%)\end{array}$ & $\begin{array}{c}389 \\
(0.11 \%)\end{array}$ & $\begin{array}{c}3582 \\
(1.01 \%)\end{array}$ & $\begin{array}{c}261 \\
(0.07 \%)\end{array}$ & $\begin{array}{c}12634 \\
(3.58 \%)\end{array}$ \\
\hline $\begin{array}{l}\text { Licenciatura } \\
\text { en } \\
\text { Educación } \\
\text { Normal }\end{array}$ & $\begin{array}{c}402 \\
(0.11)\end{array}$ & $\begin{array}{c}8658 \\
(2.45 \%)\end{array}$ & $\begin{array}{c}481 \\
(0.13 \%)\end{array}$ & $\begin{array}{c}6769 \\
(1.92 \%)\end{array}$ & $\begin{array}{c}646 \\
(0.18)\end{array}$ & $\begin{array}{c}16956 \\
(4.81 \%)\end{array}$ \\
\hline $\begin{array}{l}\text { Licenciatura } \\
\text { Universitaria } \\
\text { y } \\
\text { Tecnológica }\end{array}$ & $\begin{array}{c}4231 \\
(1.20 \%)\end{array}$ & $\begin{array}{c}148523 \\
(42.19 \%)\end{array}$ & $\begin{array}{c}13927 \\
(3.95 \%)\end{array}$ & $\begin{array}{c}84850 \\
(24.10 \%)\end{array}$ & $\begin{array}{c}23299 \\
(6.61 \%)\end{array}$ & $\begin{array}{l}274830 \\
(78.07 \%)\end{array}$ \\
\hline Posgrado & $\begin{array}{l}246 \\
(0.06 \%\end{array}$ & $\begin{array}{l}6191 \\
(1.75 \%)\end{array}$ & $\begin{array}{l}3722 \\
(1.05 \%)\end{array}$ & $\begin{array}{l}21026 \\
(5.97 \%)\end{array}$ & $\begin{array}{l}16402 \\
(4.65 \%)\end{array}$ & $\begin{array}{l}47587 \\
(13.51 \%)\end{array}$ \\
\hline Total & $\begin{array}{l}5681 \\
(1.61 \%)\end{array}$ & $\begin{array}{l}170972 \\
(48.57 \%)\end{array}$ & $\begin{array}{l}18519 \\
(5.26 \%)\end{array}$ & $\begin{array}{l}116227 \\
(33.01 \%)\end{array}$ & $\begin{array}{l}40608 \\
(11.53 \%)\end{array}$ & $\begin{array}{l}352007 \\
(100 \%)\end{array}$ \\
\hline
\end{tabular}

Nota: Elaboración propia a partir de los datos de ANUIES, 2015.

Aunado a la labor de las profesoras y los profesores universitarios en el marco de su formación profesional en materia tecnocientífica, como lo propone el Programa PRODEP, también es de suma importancia reconocer que en México ha crecido la relevancia del trabajo del profesorado universitario en su dimensión social como también en su compromiso ético y moral en las IES. Hoy, se magnifica la misión del personal docente universitario en su función de construir seres humanos, como refiere Timaná (2006):

Capaces de desarrollar sus potencialidades y competencias, de asumir con criterio su autonomía, con ideales, valores y principios éticos, con capacidad de análisis crítico, con sentido de lo estético y de trascendencia, conscientes de una cosmovisión; comprometidos con la historia regional y nacional, con el cambio social y con la capacidad de generar soluciones, de manera individual y colectiva, a los problemas regionales y nacionales con visión global. (p. 193)

Así, el personal docente universitario en México transita como un mediador entre los simbolismos, percepciones, costumbres y progresos, pasados y presentes en el colectivo social, y el desarrollo extraordinario y vertiginoso que se sucede e incide en las nuevas generaciones. Para ello, como menciona De la Herrán (2001, p. 18), debe ser un "investigador de su quehacer para la mejora en espiral de su práctica docente, como imperativo de compromiso profesional, con la siempre fundamental tarea de educar". Si el personal docente universitario desea comunicar y trasferir este conocimiento, debe estar imbuido en él; esto es, debe manifestar una sólida formación profesional como lo concibe el PRODEP, pero también debe contar con contenidos culturales consolidados en su persona.

[Para] desempeñar eficientemente esta profesión es necesario saber los conocimientos requeridos por la misma (componente técnico) y, a su vez, un ejercicio eficaz de estos necesita un saber hacer (componente metodológico), siendo cada vez más imprescindible e importante en este contexto laboral en constante evolución saber ser (componente personal) y saber estar (componente participativo). (Mas Torelló, 2011, p. 197)

Así, en México, la labor del profesorado universitario en la actualidad tiene que ser conceptualizada, en función del impacto en la formación de estudiantes, que deben manifestar particularmente actitudes y competencias, en cómo buscan, procesan y aplican el conocimiento. Sin duda, las funciones docentes que 
estamos mencionando solo se percibirán, si se relacionan con los contextos en que subsisten, como pueden ser el exosistema, que atañe al entorno sociocultural y profesional; el mesosistema, constituido por el entorno de la universidad, facultad y departamento y, finalmente, el microsistema, referido al aula y laboratorio. Sitios donde se descubren los pensamientos y las posturas humanas más profundas que han de tratar de esclarecer y definir la realidad en que se subsiste (Guichot, 2005).

Reflexionando sobre lo anterior, Guzmán (2011) menciona que los rasgos más relevantes de un buen personal docente universitario, situándolo en el ámbito del aula y laboratorio, son:

Comparte su pasión y entusiasmo por su materia explicitando a los alumnos la importancia de la misma. Vincula su labor de investigación con los temas enseñados.

Liga lo revisado en clase con tópicos o temas de actualidad.

Usa ejemplos claros y relevantes para ilustrar el tema expuesto; Indaga sobre las experiencias del estudiante y las utiliza en su enseñanza.

Plantea preguntas clave para señalar los puntos controversiales de un campo, o los problemas no resueltos o de las perspectivas existentes.

Emplea sitios de Internet para demostrar la actualidad del material presentado. (p. 136-137)

Con esto, el aula se constituye en el recinto de actuación, en un efectivo espacio de aprendizaje, y convierte la instrucción en una oportunidad participativa y dinámica, entre la profesora o el profesor universitario y sus estudiantes. En este sentido, Escámez Sánchez (2013) plantea:

La clave para comprender la docencia de los mejores profesores universitarios no puede encontrarse en reglas o prácticas concretas, sino en sus actitudes, en su fe en la capacidad de logro de sus estudiantes, en su predisposición a tomar en serio a sus estudiantes y dejarlos que asuman el control de su propia educación. (p. 19)

Por otra parte, también se debe hacer hincapié en que el profesorado universitario en nuestro país debe prevalecer y subsistir, de manera irrenunciable e inexcusable a las actividades de docencia como de investigación, que es donde se genera y aplica el conocimiento innovador. De esta manera, aunado a la gestión académica individual o colegiada, la cual consiste en llevar a cabo actividades académicas-administrativas, también resulta importante la tutoría de estudiantes (Barrón, 2009, Mas Torrello, 2011). Con ello, se pretende impactar de manera significativa en el estudiantado en México, orientándole y dotándole de herramientas para aprender a aprender, como señala Cerrillo e Izuzquiza (2005). Mostrándose, además, al profesorado universitario como "un profesional reflexivo, investigador en su propia situación docente, procesador activo de información, un profesional que toma decisiones y que se presenta como investigador en el aula" (Guichot, 2005, p.132).

¿Qué implica en México erigirse como una profesora o profesor universitario? Pues bien, involucra constituirse en sujeto guía y orientador del aprendizaje, permitiéndoles a sus estudiantes edificar su propio conocimiento, a partir de mostrarles lo que es útil y significativo, tratando así de superar las formas empobrecidas de desempeño docente y de sistemas poco plausibles de articulación con el alumnado. Esto es, "sentirse responsable directo por lo que hace o deja de hacer un alumno en la práctica profesional es un motivo que ayuda a cuestionar y a intentar cambiar la actuación en el aula y por ende los contextos de significado que la orientan", como advierte Luprecio-Nuñez (2014, p. 22). Además, el ser docente de universidad implica, como argumenta López Zavala (2013, p. 149), un proceso en el cual "sujetos intelectuales que trabajan con el conocimiento y la formación de la juventud buscando hacer el bien a la sociedad, teniendo en cuenta los desafíos que el mundo competitivo, injusto y controvertido está presentando a la educación superior”. Y, para ello, es importante conjuntar en el estudiantado, mediante la labor del profesorado universitario, el intelecto y la voluntad de hacer, para lograr una verdadera concientización, como asevera Freire (2007), que conlleve finalmente a mostrar la auténtica realidad. 


\section{El Profesorado UNIVERSITARIO COMO UN AgENTE ÉTICO Y MORAL EN MÉXico}

El ser profesora o profesor universitario se constituye en un reto merecedor de ser abordado principalmente porque se yergue en su figura social el trascendental papel, como propone Laudadío (2015, p. 165), de contribuir al "compromiso con la verdad [que] es una de las cuestiones más relevantes en la universidad, ya que la pregunta por la verdad fue -y debería seguir siendo- una de las razones fundamentales de su existencia”. Particularmente hoy, toma mucha importancia cuando, en el tejido social en distintas partes del mundo, se percibe una lamentable carencia de veracidad en las estructuras organizacionales edificadas por la sociedad, lo que se constituye en un padecimiento que irrumpe socialmente como una crisis de orden intelectual (Brey, Innerarity, y Mayos, 2009), como sucede en varios países de Latinoamérica y en México.

El personal docente universitario en México, al erigirse como un referente fundamental, reflexivo y crítico, que promueve el conocimiento, conlleva además la comprensión de la realidad de manera objetiva y, en su esencia, orienta hacia la búsqueda de la verdad, considerando el compromiso existente con la sociedad, y de la cual intenta hacer partícipes a sus estudiantes, favoreciendo, con ello, la aprehensión de los valores éticos y morales, como la honestidad, responsabilidad, compromiso social, disciplina y respeto (Gamboa, 2014; Hirsch, 2010; Jiménez, 2004). Lo que plantea que, en tiempos actuales, se afirme que ser docente de universidad es complicado y complejo, ya que la profesora o el profesor universitario se constituye para su alumnado, en un modelo de actuación personal y profesional. A lo que González (2004, p. 2) agrega, "ser modelo de actuación implica necesariamente el desarrollo del profesor como persona [ética y] moral”.

El personal docente universitario en México se alza como un modelo de persona ética y moral, porque es responsable de su pensar y actuar como ser humano, indistintamente donde se encuentre, y no solo está comprometido con lo que enseña, argumenta y realiza en clase. La ética y moral la podemos apreciar en la profesora o el profesor universitario. Primeramente, la ética como un comportamiento que manifiesta, desde un proceso de reflexión, elección de normas y principios que dirigen su ser, mientras que, desde la práctica, la moral se muestra conjugando criterios y valores, que conducen su hacer, donde se involucra la parte cognitiva, emocional y conductual.

Lo anterior acomete fuertemente en la conciencia y pensamiento del estudiantado, al esbozar una doble reflexión de manera conjunta, tanto personal como profesional (García, et al., 2009), haciéndolo consciente de lo que hará y decidirá tanto en lo individual como en lo colectivo. Dado que el profesorado universitario crea una sinergia con su persona, que conduce al estudiantado por el camino del desarrollo ético y moral, cuyo objetivo es formar seres humanos íntegros, con criterio y sensibilidad, congruentes con su decir y hacer; pero además va configurando, explícita o tácitamente, el carácter de cada estudiante (Torres Narváez, 2006). Lo antes aludido confirma la aseveración que Savater (2001, p. 96) realiza, al indicar que "los seres humanos somos temporales y aprendemos la temporalidad de los otros".

La formación integral estudiantil, y en particular del aspecto ético y moral, requiere de un cuerpo docente universitario en México comprometido con ese propósito, donde impere el siguiente principio, como aduce Cortina (2002, p. 55) al hacer alusión a Immanuel Kant, "obra de tal modo que trates a la humanidad, tanto en tu persona como en la de cualquier otro, siempre al mismo tiempo como un fin y nunca simplemente como un medio". Esto representa que la profesora o el profesor universitario, en nuestro país, debe favorecer la formación integral de la personalidad de sus estudiantes, no solo proveyendo el conocimiento, sino estimulando actitudes positivas y respaldando prácticas y hábitos que favorezcan los valores éticos y morales (Ayuso y Gutiérrez, 2007). En otros términos, como afirma Paukner Nogués (2007, p. 2) al hacer referencia a las ideas expresadas por Kant en su libro Pedagogía:

Cada generación educa a otra y mejora lo hecho por la generación precedente. Los hombres ilustrados deben ser los gestores de la educación en función de lograr una persona:

Disciplinada: poseedora de una humanidad sin animalidad

Cultivada: dotada de instrucción y enseñanza 
Prudente: con desarrollo a la civilidad

Moral: con capacidad para adecuar fines y medios.

Gravita su actuación, en el marco de la exposición de los saberes aristotélicos, que confluyen en las tres dimensiones principales de la existencia humana, que son el aprender, crear y actuar. Acorde con Cortina y Martínez (2008), estos saberes aristotélicos versan sobre los saberes teóricos, que se ocupan de examinar cuáles son las causas de los acontecimientos, los saberes poéticos, que establecen pautas orientadoras para la elaboración de artilugios útiles y, finalmente, los saberes prácticos, que se constituyen en normas que nos orientan en cómo debemos conducirnos en la vida.

Consiguientemente, la formación integral de este nuevo capital humano y social en México, resaltado en el alumnado, comienza y se materializa a través de las acciones cotidianas del profesorado universitario, en la dialéctica que surge entre sí en las aulas, donde se forjan las personalidades de las nuevas generaciones; circundada esta relación por las numerosas exigencias, progresivas, complejas y hasta discordantes que emanan del tejido social. Es así como resulta imprescindible que la docencia se ejerza con suma responsabilidad en la universidad, valiéndose además de la ejecución de acciones como: la preparación de materiales que ubiquen al alumnado frente a la realidad en que subsiste, el desarrollo de actividades donde abiertamente se deliberen, la realización de foros de debate y discusión en un marco de carácter social, creación de espacios para el intercambio de buenas prácticas y experiencias (Ruiz, Jerome y Domínguez, 2013).

En esta dialéctica entre profesorado universitario y estudiante, en términos generales, el personal docente debe, desde el marco de responsabilidad, asegurarse de proporcionar elementos técnicos suficientes para la retención, continuidad y aplicabilidad de los saberes profesionales, como también enseñar los métodos para crear nuevos conocimientos científicos y, finalmente, proveer habilidades interpersonales a sus estudiantes, más allá de los conocimientos profesionales requeridos, con la finalidad de manifestar rasgos de empatía y sensibilidad a las necesidades de los otros individuos, a través de valores éticos y morales, componentes relevantes de las orientaciones que puede seguir una acción determinada. Sustentando esto en un optimismo influencial, que se relaciona con el convencimiento de que existe la probabilidad y el deber de rehacer la sociedad y orientarla hacia un futuro mejor, donde se procura y fortalece como un bien social; distinto al optimismo esencial, que señala que el futuro sobrevendrá, simple y llanamente sin la mediación humana (Gómez, 2010).

Por esta razón, las dimensiones éticas y morales deben ser reorganizadas metacongnitivamente de forma constante en la docencia universitaria, promoviendo una discusión racional, con disensos y consensos; pero esencialmente admitiendo la diversidad y reconocimiento de la otra persona, debido al cambiante poder de elección con el que cuenta el ser humano y de la legitimación que se origina de las acciones en la sociedad, producto de los avances técnicos y científicos, como también de carácter sociocultural. De ello, sumariamente, Garrido (2011, p. 16) da testimonio, al hacer alusión a Habermas, al indicar que todo argumento esgrimido o acción comunicativa, como acontece en la docencia universitaria, "puede ser criticado como no verdadero en lo que concierne al enunciado hecho, como no correcto en lo que concierne a los contextos normativos vigentes, y como no veraz en lo que concierne a la intención del hablante". Este pronunciamiento se torna de suma importancia cuando en el ámbito de la enseñanza universitaria se desea lograr la formación moral y ética del ser humano, por lo tanto, debe subsistir una conciliación racional entre los agentes interlocutores que participan, donde el contexto situacional de la realidad debe ser tomado en cuenta, aunque se encuentre con mucha corrupción, ya que en el arte de la educación superior, ejercida por el personal docente universitario, debe prevalecer el razonamiento con la finalidad de desplegar toda la naturaleza humana del estudiantado a través de recibir instrucción y educación para tomar decisiones en progreso de una mayor civilidad y que estas le encaminen a un ejercicio racionalmente independiente en su comportamiento.

Por tal motivo, la profesora o el profesor universitario ha de valerse, como asevera Quintero (2012, p. 26), de la ética que se constituye en "el modelo ideal de la moral de los individuos"; con lo cual, articula la docencia universitaria de un modo más reflexivo para dotarla de sentido humano; donde las percepciones, ideas, 
experiencias, conocimientos y destrezas acumuladas deriven en sus aportes, que este ser individual y colectivo, realiza a la sociedad a través de la formación, tanto de seres humanos como de una ciudadanía, lo cual recae en sus estudiantes (Vaillant, 2008). Y que, desde la dimensión ética, le demanda juicios profesionales de forma incesante, que ha de resolver en la práctica, de acuerdo con la ocupación que socialmente le responsabiliza públicamente; pero, además, como advierte Del Mastro y Monereo (2014, p. 5), "repercute en la identidad del profesor universitario, sus prácticas y concepciones sobre su labor de enseñanza”.

\section{Conclusiones}

Para enunciar cuál es el papel del profesorado universitario en la trasmisión de valores éticos y morales en la docencia en educación superior en México, es ineludible prestar atención a la práctica docente desde las diferentes IES donde esta se realice, debido a que las actividades que lleva a cabo el personal docente universitario en las IES está acorde con los lineamientos especificados en cada una de estas donde trabajan, y a que, en muchas ocasiones, esta actividad docente se ve influenciada por organismos de carácter nacional e internacional, que delimitan la atribución y requerimientos a partir de políticas públicas educativas.

Además, anticipadamente se comprende, que la persona docente universitaria se ve obligada a deliberar sobre su práctica educativa, particularmente porque todo acto proyectado por ella, repasa sus motivos, los cuales, de acuerdo con los principios kantianos, el valor ético y moral que surja de toda acción que emprenda, no residirá en el valor de la acción, sino únicamente en el principio que motiva tal acción, que debe ser la buena voluntad y del compromiso de hacer un bien a las personas; es así que la ética se erige como un deber e intenta, mediante esto, concebir al ser humano en un ser moral. En otras palabras, el deber ser del personal docente universitario emergerá como un propósito o intención comprometida, donde el vocablo $<$ deber $>$ contendrá la buena voluntad con la finalidad de hacer viable la realización de buenas prácticas, que se puedan reconocer en la vinculación <ética-educación>. Esta educación ejercitada sobre sus estudiantes habrá de distinguirse por dotar el carácter moral, mediante disposiciones y ejemplos, que conlleven tanto los deberes con las demás personas, como también aquellos otros deberes para consigo. Sin más, así se erigirá al ser humano moral, haciéndole transitar de la animalidad a la racionalidad moral. Caracterizada esta última por la civilidad, prudencia y la razonable práctica de la libertad.

Por otra parte, tomando en cuenta las consideraciones antes mencionadas, el derrotero que conduce a una identidad ética y moral del personal docente universitario en México sucede a través de dos vías, que se entrecruzan: el rubro de la relación natural que surge entre docentes y estudiantes, que supera profusamente el plano del salón de clases y, finalmente, por la profesión misma, que conlleva una natural intencionalidad de tener injerencia y mediar en la edificación del estudiantado. Esta connotación del profesorado universitario, conforme con Dena Romero (2002, p. 23), es muy importante ya que "se le confía la juventud para que la forme integralmente en el sentido platónico de la educación, de darle al cuerpo y alma toda la perfección de que sean susceptibles ... forja el porvenir humano".

Esto toma mucha relevancia en la actualidad, cuando el avance tecnológico, plasmado en dispositivos digitales, está reconfigurando la socialización estudiantil, pues en estos están encontrando un espacio de experiencia y subjetivación, que les está poseyendo, alejándoles de prácticas y encuentros con las personas, y que pueden, en el futuro, afectar las actuaciones y expresiones en su proceder, carentes de valores éticos y morales experimentados. Cito a Savater (2001, p. 99), para responder a la pregunta que planteamos sobre la labor del profesorado universitario. Esencialmente esta debe consistir en "trasmitir el fervor intelectual por lo humano, por el conocimiento, por lo valores compartidos y por los valores humanistas”. Y añado finalmente lo que Freire (2007) advierte a través de su discurso y obra: el ser humano representado en este caso en la figura de la profesora o el profesor universitario debe asumir su papel de individuo que crea y renueva el mundo, en un contexto dialéctico con sus estudiantes, que permita construir seres humanos protagonistas de su propia 
historia, en un escenario de libertad, igualdad y compromiso por transformar la realidad, en espacio y tiempo, en un ámbito cada vez más justo.

\section{ReFERENCIAS}

Asociación Nacional de Universidades e Instituciones de Educación Superior. (2015). Anuario Estadístico Personal Docente en Educación Superior. Ciclo Escolar 2012-2013. México: ANUIES.

Arévalo Cisneros, G. A. (2007). La ética y su relación con las normas en grupos universitarios de investigación (Tesis de licenciatura, inédita). México. Universidad Nacional Autónoma de México.

Ayuso Marente, J. A. y Gutiérrez Nieto, C. (2007). Educación en valores y profesorado. Revista Educación en Valores, 1(7), 108-118. Recuperado de http://servicio.bc.uc.edu.ve/multidisciplinarias/educacion-en-valores/ v1n7/v1n72007-13.pdf

Barrón Tirado, M. C. (2009). Docencia universitaria y competencias didácticas. Perfiles Educativos, 31(125), 76-87. Recuperado de http://www.scielo.org.mx/scielo.php?script=sci_arttext\&pid=S0185-26982009000300006

Brey, A., Innerarity, D. y Mayos, G. (2009). La sociedad de la ignorancia. Barcelona: Infonomía.

Camarillo Hinojosa, H. M. (2002). La educación superior como infraestructura del desarrollo económico y social de México. Didactikón, 1(2): 25-30.

Cantú-Martínez, P. C. (2013). Las instituciones de educación superior y la responsabilidad social en el marco de la sustentabilidad. Revista Electrónica Educare, 17(3), 41-55. Recuperado de http://www.scielo.sa.cr/pdf/ree/ v17n3/a03v17n3.pdf

Cantú-Martínez, P. C. (2014). La bioética en las Instituciones de educación superior en el contexto de la sustentabilidad. Ciencia UANL, 17(65), 24-30. Recuperado de http://cienciauanl.uanl.mx/?p=780

Cantú-Martínez, P. C. (2015a). Bioética y educación superior en México. Acta Bioethica, 21(1), 45-52. Recuperado de http://www.scielo.cl/scielo.php?script=sci_arttext\&pid=S1726-569X2015000100006

Cantú\#-Martínez P. C. (2015b). Bioética e investigación en salud (3era. Ed.). México: Trillas.

Cerrillo, M. R. y Izuzquiza, D. (2005). Perfil del profesorado universitario. Revista Interuniversitaria de Formación del Profesorado, 8(5), 1-5. Recuperado de http://www.redalyc.org/articulo.oa?id=217017180002

Chapela, M. del C. y Cerda, A. (2010). Ethos, conocimiento y sociedad. Reencuentro; 57, 18-24. Recuperado de http://www.redalyc.org/articulo.oa?id=34012514003

Chávez, G. y Benavides, B. (2011). Los profesores universitarios: Entre la exigencia profesional y el compromiso ético-social. Sinéctica, 37, 1-13. Recuperado de http://www.scielo.org.mx/scielo.php? script $=$ sci_arttext\&pid=S1665-109X2011000200003

Cortina, A. (Mayo-agosto, 2002). La dimensión pública de las éticas aplicadas. Revista Iberoamericana de Educación, 29, 45-64. Recuperado de http://rieoei.org/rie29a02.htm

Cortina, A. y Martínez, E. (2008). Ética. Madrid. Ediciones Akal.

Cullen, C. (2004). Perfiles ético-políticos de la educación. Buenos Aires: Paidós.

De la Herrán Gascón, A. (2001). Didáctica universitaria: La cara dura de la universidad. Tendencias Pedagógicas, 6, 11-38. Recuperado de https://dialnet.unirioja.es/servlet/articulo?codigo $=239676$

Del Mastro, C. y Monereo, C. (2014). Incidentes críticos en los profesores universitarios de la PUCP. Revista Iberoamericana de Educación Superior, 5(13), 3-20. Recuperado de

Delgado, J. E. (2007). Academia cambiante y papel de profesor universitario. Universitas Odontológica, 26(58), 4-5. Recuperado de http://www.redalyc.org/articulo.oa?id=231218562001

Dena Romero, O. (2002). La ética profesional del magisterio. Didactikón, 1(2), 21-30.

Escámez Sánchez, J. (2013). La excelencia en el profesor universitario. Revista Española de Pedagogía, 71(254), 11-27. Recuperado de http://revistadepedagogia.org/index.php/es/ano-2013/125-no-254-enero-abril-2013/586-laexcelencia-en-el-profesor-universitario 
Freire, P. (2007). La educación como práctica de la libertad. México: Siglo XXI Editores.

Gamboa Tortolero, F. J. (2014). Etnoética del docente universitario en el siglo XXI. Una aproximación teórica (Tesis de doctorado, inédita). Venezuela. Universidad de Carabobo.

García, R., Sales, A., Moliner, O. y Fernández, R. (2009). La formación ética profesional desde la perspectiva del profesorado universitario. Teoría de la Educación, 21(1), 199-221. Recuperado de http://repositori.uji.es/ xmlui/handle/10234/67620

Garrido Vergara, L. (2011). Habermas y la teoría de la acción comunicativa. Razón y Palabra, 75, 1-19. Recuperado de http://www.razonypalabra.org.mx/N/N75/ultimas/38_Garrido_M75.pdf

Gómez Ávila, L. M. (2010). Utopía, anti-utopía y educación En M. C. Barrón Tirado (Coord.), Retos y desafíos de la educación superior (pp. 21-40). Madrid: Ediciones Díaz de Santos/UNAM.

González Maura, V. (2004). El profesorado universitario: Su concepción y formación como modelo de actuación ética y profesional. Revista Iberoamericana de Educación, 33(7), 1-11. Recuperado de http://rieoei.org/ edu_sup29.htm

Gorrochotegui, A. (2005). Compromisos de la docencia universitaria. Educación y Educadores, 8, 105-121. Recuperado de http://www.redalyc.org/articulo.oa?id=83400809

Guichot Reina, V. (2005). Armonizar lo local y lo global, un reto para el docente: Algunas reflexiones desde la práctica universitaria. En Peiró i Gregori, S. (Coord.), Nuevos desafíos en educación (Tomo II, pp. 131-138). España: Editorial Club Universitario.

Guzmán, J. C. (2011). La calidad de la enseñanza en educación superior. ¿Qué es una buena enseñanza en este nivel educativo? Perfiles educativos, 33(Especial), 129-141. Recuperado de http://www.redalyc.org/articulo.oa? id $=13221258012$

Hirsch Adler, A. (2010). Ética profesional y profesores universitarios: Una perspectiva comparativa. Reencuentro, 57, 34-38. Recuperado de http://www.redalyc.org/articulo.oa?id=34012514005

Jiménez Orozco, M. (julio-diciembre, 2004). El profesor universitario y el perfil académico. Pampedia, 1, 1-7. Recuperado de https://www.uv.mx/pampedia/numeros/numero-1/profesor-universitario-perfilacademico.pdf

Knight, P. T. (2006). El profesorado de educación superior. España: Narcea.

Laudadío, J. (2015). Ser profesor universitario, desafío digno de ser emprendido. Perspectiva Educacional, 54(1), 163-177. Recuperado de http://bit.ly/2Bk3zNf

Linares Márquez, P. y Fraile Laiz, B. (2012). Bioética y universidad en América Latina. Propuesta de una estructura para la formación integral profesional. Revista Colombiana de Bioética, 7(2), 120-133. Recuperado de http:// www.redalyc.org/articulo.oa?id=189225524009

Lolas Stepke, F. (2002). Bioética y medicina: Aspectos de una relación. Santiago de Chile: Editorial Biblioteca Americana.

López Zavala, R. (2013). Ética de la docencia universitaria. La dimensión social en la cultura profesional del profesorado. Edetania, 43, 147-159. Recuperado de https://dialnet.unirioja.es/descarga/articulo/4406438.pdf

Lupercio-Núñez, P. (2014). Los significados de la docencia en los profesores de educación superior (Tesis de doctorado, inédita). México. Instituto Tecnológico y de Estudios Superiores de Occidente.

Mas Torello, O. (2011). El profesor universitario: Sus competencias y formación. Profesorado. Revista de Currículum y Formación de Profesorado, 15(3), 195-211. Recuperado de http://www.ugr.es/ recfpro/rev153COL1.pdf

Masiá Clavel, J. (1995) ¿Qué educación y para que persona? En Aula de Ética (Ed.), La ética en la universidad. Orientaciones básicas (pp 11-24). Bilbao: Universidad de Deusto.

Mungaray, A., Ocegueda, J. M. y Sánchez M. D. (2002). Retos y perspectivas de la reciprocidad universitaria a través del servicio social en México. México: Miguel Ángel Porrúa / Universidad Autónoma de Baja California.

Paukner Nogués, F. (2007). La pedagogía en Kant. Una exégesis de su libro Pedagogía. A Parte Rei: 52, 1-4. Recuperado de http://serbal.pntic.mec.es/ cmunoz11/paukner52.pdf 
Quintero, J. (2012). Incidencia de los valores individuales para alcanzar las competencias éticas en la formación del docente universitario. REDHECS, Revista electrónica de Humanidades, Educación y Comunicación Social, 7(13), 20-37. Recuperado de https://dialnet.unirioja.es/servlet/articulo?codigo=4172889

Ross, A. (2010). La emergencia de la universidad global. Capturas y fugas en el mercado global del saber. En Edu-Factory y Universidad Nómada (Comps.), La universidad en conflicto (pp. 51-70). Madrid: Traficantes de Sueños.

Ruiz, M., Jerome, C. y Domínguez, F. (2013). Cómo se entiende la cooperación al desarrollo desde la universidad. En R. M. Rodríguez Jiménez. (Coord.), Educación en valores en el ámbito universitario. Propuestas y experiencias (pp. 31-44). Madrid: Narcea.

Sánchez Puente, R. (2014). Enseñar a investigar. Una didáctica nueva de la investigación en ciencias sociales y humanas. México. Universidad Nacional Autónoma de México.

Savater, F. (2001). El valor de educar. Educere, 5(13), 93-102. Recuperado de http://www.redalyc.org/ $\mathrm{pdf} / 356 / 35601319 . \mathrm{pdf}$

Secretaría de Educación Superior. (27 de diciembre, 2014). Acuerdo número 23/12/14 por el que se emiten las Reglas de Operación del Programa para el Desarrollo Profesional Docente para el ejercicio fiscal 2015. Diario Oficial de la Federación en México.

Timaná Velásquez, Q. (2006). El profesor, centro de la vida universitaria. Educación y Educadores, 9(1), 191-196. Recuperado de http://www.scielo.org.co/scielo.php?script=sci_arttext\&pid=S0123-12942006000100013

Torres Narváez, M. R. (2006). El profesor universitario, un agente de desarrollo moral. Revista de Ciencias de la Salud, 4(Especial), 103-109. Recuperado de http://www.redalyc.org/articulo.oa?id=56209912

Vaillant, D. (2008). Educación, socialización y formación de valores cívicos. Brasil: iFHC/CIEPLAN.

Zabalza, M. A. (2004). La enseñanza universitaria. El escenario y sus protagonistas. España: Narcea.

CC BY-NC-ND 